\title{
Correction
}

\section{Correction: Sturm et al., Development of Intrinsic Connectivity in the Central Nucleus of the Mouse Inferior Colliculus}

In the article "Development of Intrinsic Connectivity in the Central Nucleus of the Mouse Inferior Colliculus" by Joshua Sturm, Tuan Nguyen, and Karl Kandler, which appeared on pages 15032-15046 of the November 5, 2014 issue, the authors regret errors discovered in some of the figures. In Figure $1 B$, an averaged map instead of a single-trial map was shown, and in Figure $1 D$, the map for TTX at -65 $\mathrm{mV}$ was inadvertently shown for both $-65 \mathrm{mV}$ and $0 \mathrm{mV}$. Additionally, in Figure $1 D$, a single map was shown instead of an averaged map for the "Average Map" in the top row, and an averaged map was shown instead of a single map for "Map 1" in the bottom row. The corrected figure is shown below. In Figures $2 C$ and $5 B i$, the $y$-axis labeling was given as "Input Area $\left(\mu \mathrm{m}^{2}\right)$," but the correct labeling is "Input Area $\left(\times 10^{3} \mu \mathrm{m}^{2}\right)$." None of these errors affect the results or the conclusions of the manuscript.

A
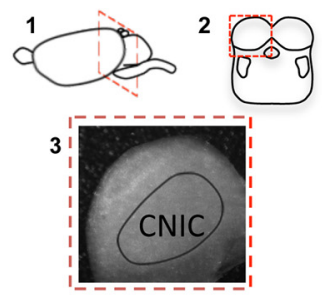

D
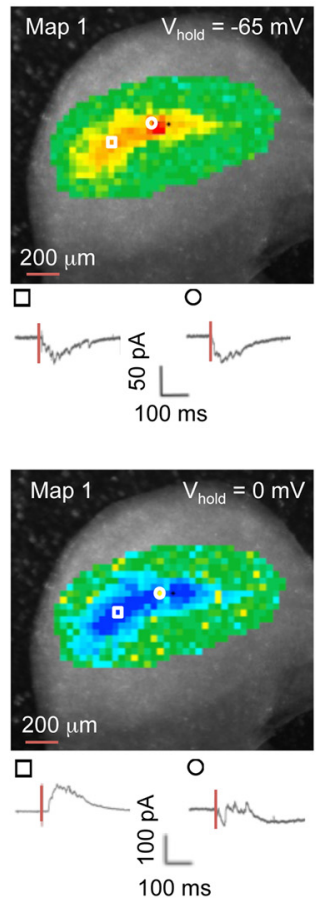

B
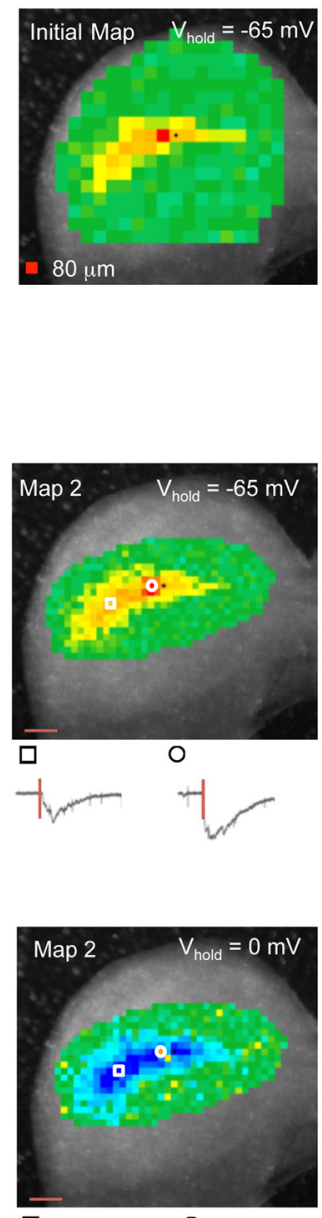

$\square$

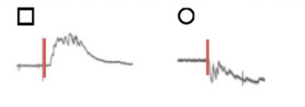

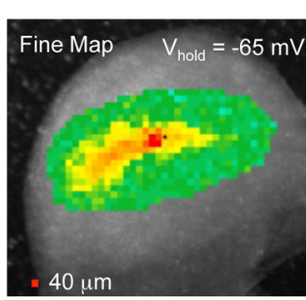

Synaptic

Charge $(p C)$

10
0
-10
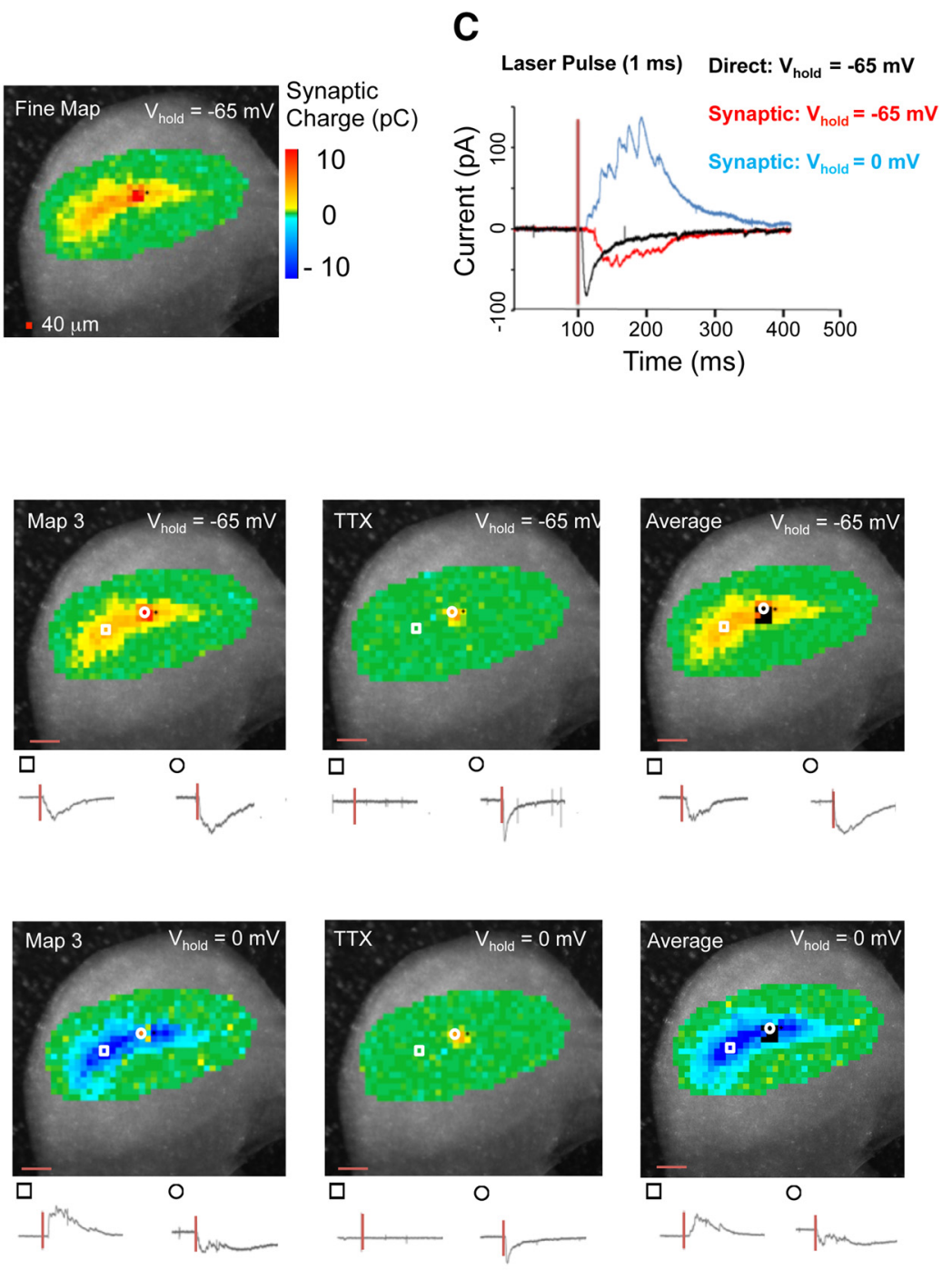

Figure 1. 